\title{
Corrosion Behavior of $9 \%$ Ni Steel for LNG Storage Tanks in 3.5 wt. \% NaCl Solution
}

\author{
Ming Qin ${ }^{1,2}$, Weichen $X u^{1,3}$, Lihui Yang ${ }^{1,3}$, Yantao $\mathrm{Li}^{1,3, *}$ \\ ${ }^{1}$ CAS Key Laboratory of Marine Environmental Corrosion and Bio-fouling, Institute of Oceanology, \\ Chinese Academy of Sciences, Qingdao 266071, China. \\ ${ }^{2}$ University of Chinese Academy of Sciences, Beijing 100049, China. \\ ${ }^{3}$ Open studio for marine Corrosion and Protection, Qingdao National Laboratory for Marine Science \\ and Technology, Qingdao 266071, China. \\ *E-mail: ytli@qdio.ac.cn
}

doi: $10.20964 / 2018.07 .24$

Received: 26 February 2018 / Accepted: 4 April 2018 / Published: 5 June 2018

The corrosion behavior of $9 \% \mathrm{Ni}$ steel in a 3.5 wt. $\% \mathrm{NaCl}$ solution was investigated by electrochemical techniques including open circuit potential (OCP), potentiodynamic polarization, and electrochemical impedance spectroscopy (EIS). The principal components and morphology of $9 \% \mathrm{Ni}$ steel and the resulting corrosion layer are analysed by metallographic evaluation, scanning electron microscopy (SEM), energy-dispersive spectroscopy (EDS), Raman spectroscopy, X-ray diffraction (XRD) and Fourier transform infrared spectroscopy (FTIR). The results suggest that the anodic reaction is primarily the dissolution of the iron matrix and the cathodic process is mainly the reduction of oxygen. The corrosion resistance $\mathrm{R}_{\mathrm{ct}}$ of $9 \% \mathrm{Ni}$ steel decreased with increasing immersion time and the corrosion layer did not provide protection. The outer section of the corrosion product consists mostly of lepidocrocite $\gamma$-FeOOH, trace goethite $\alpha-\mathrm{FeOOH}$, and magnetite $\mathrm{Fe}_{3} \mathrm{O}_{4}$. The inner section is a nickel-rich layer, which is related to the alloying elements and reverted austenite. Moreover, the corrosion layer was found to accelerate the selective corrosion.

Keywords: $9 \%$ Ni steel; corrosion; electrochemical tests; reverted austenite; nickel-rich layer

\section{$\underline{\text { FULL TEXT }}$}

(C) 2018 The Authors. Published by ESG (www.electrochemsci.org). This article is an open access article distributed under the terms and conditions of the Creative Commons Attribution license (http://creativecommons.org/licenses/by/4.0/). 